\title{
WORKSHOP PENYUSUNAN MODUL PADA MGMP MATEMATIKA SMK MALANG
}

\author{
Tri Candra Wulandari ${ }^{1}$, Sri Rahayu ${ }^{2}$, Yuniar Ika Putri Pranyata ${ }^{3}$ \\ ${ }^{1,3}$ Prodi Pendidikan Matematikai, ${ }^{2}$ Prodi Pendidikan Guru Sekolah Dasar, \\ ${ }^{1,3}$ Fakultas Sains dan Teknologi, ${ }^{2}$ Fakultas Ilmu Pendidikan \\ ${ }^{1,2,3}$ Universitas Kanjuruhan Malang \\ ${ }^{1}$ fikri.chan@unikama.ac.id
}

\begin{abstract}
ABSTRAK
Memiliki latar belakang keilmuan yang berbeda dengan SMA, tentunya membuat guru SMK lebih kreatif dalam mengajar, kreatif dalam menciptakan media pembelajaran maupun sumber belajar. Selama ini, fokus pengembangan hanya berdasarkan pada kondisi fisik dan pengembangan pembelajaran, pengembangan SDM belum sampai pada masalah content setiap mata pelajaran. Hingga saat ini masih belum ada solusi nyata yang mampu mengatasi kelemahan pemahaman konsep peserta didik terutama pada mata pelajaran matematika. Pengabdi memberikan solusi agar guru membuat modul. Modul merupakan salah satu bentuk bahan ajar cetak yang dapat digunakan guru sebagai percepatan pembelajaran. Kegiatan yang dilaksanakan adalah workshop dengan strategi pelatihan selama satu minggu dengan rincian kegiatan pelatihan meliputi teori, praktik dan presentasi. Pengabdian pada masyarakat dalam bentuk workshop penyusunan modul kontekstual pada guru SMK Malang adalah (a) menyusun modul matematika yang memiliki karakteristik program keahlian, (b) soal yang disusun merupakan soal matematika yang dikaitkan langsung dengan permalahan sesuai dengan kompetensi keahlian.
\end{abstract}

\section{Kata-kata kunci : workshop, modul, kontekstual, MGMP matematika SMK}

\begin{abstract}
Having a different scientific background with high school, makes vocational's teachers more creative in teaching, be creative in learning media and learning resources. So far, the focus of development is based on the physical condition and development of learning, human resource development has not reached the subject matter content of each subject. Until now there is still no real solution that can overcome the weakness of understanding the concept of learners, especially on the subjects of mathematics. Servers provide solutions for teachers to create modules. Module is one form of printed material that teachers can use as an acceleration of learning. The activities undertaken are workshops with a one week training strategy with detailed training activities covering theory, practice and presentation. Community service in the form of a workshop on the preparation of contextual modules in teachers of SMK Malang is (a) preparing math modules that have characteristics of skill program, (b) the matter that is composed is a mathematical problem that is directly related to the error in according with the competence of expertise
\end{abstract}

Keywords : contextual, module, teacher vocational school, workshop 


\section{PENDAHULUAN}

\subsection{Analisis Situasi}

Memiliki latar belakang keilmuan yang berbeda dengan SMA, tentunya membuat guru SMK lebih kreatif dalam mengajar, kreatif dalam menciptakan media pembelajaran maupun sumber belajar. Melihat fakta bahwa kurikulum SMK mewajibkan peserta didik melaksanakan Praktik Kerja Industri (Prakerin) selama kurang lebih 6 bulan atau semester, tentunya akan berimbas pada keterlaksanaan pembelajaran untuk mata pelajaran non-produktif atau kejuruan. Saat prakerin, peserta didik tidak mungkin hadir di sekolah untuk mengikuti pelajaran non-produktif seperti, matematika, bahasa inggris, IPA dan mata pelajaran lainnya. Oleh karena itu, perlu adanya kiat mengatasi masalah akademis apabila peserta didik mulai prakerin.

SMK Negeri 2 Malang, merupakan salah satu SMK besar di Malang. SMK Negeri 2 telah mencanangkan akan menjadi SMK Rujukan. Saat ini, SMK Negeri 2 Malang telah menggandeng beberapa SMK swasta di kota Malang sebagai SMK partner. Sebagai sekolah rujukan, SMK Negeri 2 Malang berusaha memberikan layanan optimal kepada seluruh SMK partner dan seluruh masyarakat. Salah satu layanan bagi SMK yang tergabung adalah kemudahan akses informasi dan peningkatan kualitas SDM.

Selama ini, fokus pengembangan hanya berdasarkan pada kondisi fisik dan pengembangan pembelajaran, pengembangan SDM belum sampai pada masalah content setiap mata pelajaran. Hingga saat ini masih belum ada solusi nyata yang mampu mengatasi kelemahan pemahaman konsep peserta didik terutama pada mata pelajaran matematika.

Selain lemahnya pemahaman konsep, kendala utama adalah bagaimana memelihara konsep matematika saat peserta didik menempuh Prakerin. Saat siswa prakerin, guru selalu disibukkan dengan kegiatan evaluasi saat siswa kembali dari prakerin. Pada umumnya, jadwal peserta didik yang kembali dari Prakerin pada saat mendekati Ujian Semester. Akibatnya, guru berlombalomba mengumpulkan nilai untuk $d i$ upload dalam sistem

Berdasarkan masalah yang disampaikan, Pengabdi memberikan solusi agar guru membuat modul. Modul merupakan salah satu bentuk bahan ajar cetak yang dapat digunakan guru sebagai percepatan pembelajaran (mastery learning) (Wulandari, 2016). Pembuatan modul yang ditawarkan merupakan modul bercirikan kontekstual yang disesuaikan dengan masalah nyata sesuai dengan program 
keahlian yang ada di SMK. Sebagai contoh, pada materi Statistika, semua program keahlian akan memperoleh materi yang sama, akan tetapi modul yang digunakan tidak sama, sebab isi modul disesuaikan dengan program keahlian. Program Keperawatan akan mendapat modul yang semua permasalahannya berkaitan dengan keperawatan, begitu juga bagi program keahlian perhotelan, modul yang digunakan berisi masalah yang berkaitan dengan perhotelan.

Kegiatan pengabdian ini melibatkan SMK Negeri 2 Malang dan SMK Adi Husada Malang. Pemilihan salah satu sekolah partner ini berdasarkan terdapat satu program keahlian yang sama dengan SMK Negeri 2 Malang. Sselain itu, SMK Adi Husada memiliki latar belakang permasalahan yang sama dengan SMK Negeri 2.

\subsection{Permasalahan Mitra}

Permasalahan yang dihadapi guru di sekolah adalah:

a. Keterampilan guru dalam membuat modul masih rendah

b. Kegiatan peningkatan kompetensi di sekolah tidak menyentuh aspek keterampilan menulis modul.

c. Sekolah belum memiliki bahan ajar yang dibuat oleh guru yang disesuaikan dengan program

keahlian

a. Kesulitan dalam mendatangkan pihak kompeten untuk meningkatkan kompetensi menulis modul sangat tinggi karena ketidaktahuan terhadap instruktur.

\section{METODE KEGIATAN}

Kegiatan yang dilaksanakan adalah workshop dengan strategi pelatihan selama satu minggu dengan rincian kegiatan pelatihan meliputi teori, praktik dan presentasi.

Sesuai dengan rencana kegiatan pelatihan, berikut diuraikan langkahlangkah pelaksanaan kegiatan dalam bentuk tabel rencana kegiatan pelaksanaan pelatihan.

\begin{tabular}{|c|c|c|}
\hline $\begin{array}{c}\text { Hari } \\
\text { ke- }\end{array}$ & Kegiatan & Ket \\
\hline 1 & $\begin{array}{ll}- & \text { Karakteristik modul } \\
- & \text { Modul yang sesuai } \\
& \text { dengan SMK } \\
- & \text { Melakukan analisis } \\
& \text { kebutuhan modul } \\
- & \text { Mengetahui } \\
& \text { perbedaan modul dan } \\
& \text { LKS } \\
\end{array}$ & Teori \\
\hline 2 & $\begin{array}{l}\text { - Menguasai pengetikan } \\
\text { pengolah kata sesuai } \\
\text { karakteristik modul } \\
\text { - } \text { Cara menyisipkan } \\
\text { gambar, tabel, dan } \\
\text { grafik } \\
\text { - } \text { Cara membuat dan } \\
\text { menyisipkan } \\
\text { gambar } \\
\text { - } \text { Cara menentukan } \\
\text { cover, isi dan } \\
\text { daftar isi } \\
\text { - Cara melayout } \\
\text { bookfold }\end{array}$ & Praktik \\
\hline
\end{tabular}




\begin{tabular}{lll}
$3-$ & Praktik membuat & Presentasi \\
& permasalahan pada & \\
& modul sesuai & \\
& karkateristik program & \\
& keahlian \\
& - & Praktik pengetikan \\
& layout \\
\hline
\end{tabular}

Partisipasi merupakan hal yang penting untuk keberhasilan program pelatihan ini. Partisipasi mitra yang diharapkan saat pelaksanaan pelatihan ini adalah:

a. Peserta memiliki permasalahan tentang sebaran bahan ajar yang dimilikinya

b. Peserta merupakan guru SMK yang memiliki kesungguhan dan keaktifan serta kooperatif terhadap materi yang disampaikan

c. Pihak sekolah sebagai mitra dalam pelatihan ini menyediakan sarana dan prasarana seperti ruang, LCD dan proyektor.

\section{HASIL DAN PEMBAHASAN}

Pada bulan April 2017, pengabdi memulai menemui wakil koordinator MGMPS Matematika SMKN 2 Malang yaitu Ibu Eko Minarti, untuk mendapatkan mitra yang sesuai dengan kondisi yang dibutuhkan. Wakil Koordinator MGMPS memberikan saran agar menemui perwakilan SMK Kendedes Malang serta SMK Bina Mandiri Malang. Dari hasil pertemuan ditentukan bahwa kegiatan akan dilaksanakan di SMKN 2 Malang. Pelaksanaan kegiatan pada pihak mitra adalah workshop dengan penyusunan modul kontekstual selama satu minggu dengan rincian kegiatan pelatihan meliputi teori, praktik dan presentasi.

Pada akhir bulan April 2017 pengabdi memulai menyusun handout yang akan digunakan dalam workshop. Penyusunan handout ini melibatkan mahasiswa untuk mendapatkan konten materi serta layoutnya. Kegiatan workshop baru dapat terlaksana pada tanggan 19-21 Agustus 2017. Adapun banyaknya peserta yang mengikuti workshop adalah 11 orang. Sesuai dengan rencana kegiatan pelatihan, langkah-langkah pelaksanaan kegiatan seperti berikut.

1) Kegiatan tanggal 19 Agustus 2017,
a) Karakteristik modul
b) Modul yang sesuai dengan SMK
c) Melakukan analisis kebutuhan modul
d) Mengetahui perbedaan modul dan LKS

2) Kegiatan tanggal 20 Agustus 2017,
a) Analisis kebutuhan modul
b) Menguasai pengetikan pengolah kata sesuai karakteristik modul
c) Cara menyisipkan gambar, tabel, dan grafik
d) Cara membuat dan menyisipkan gambar
e) Cara menentukan cover, isi dan daftar isi
f) Cara melayout bookfold

3) Kegiatan tanggal 21 Agustus 2017,
a) Uji coba presentasi artikel karya tulis ilmiah setiap peserta
b) Evaluasi dari presentasi setiap peserta

Hasil evaluasi di akhir diperoleh bahwa para peserta masih kesulitan dalam menyusun modul. Hal ini disebabkan oleh para guru tidak terbiasa menyusun soal matematika yang berkaitan langsung dengan kompetensi keahlian. Solusi dalam menghadapi masalah ini adalah, penyusunan modul dan soal latihan dilakukan dengan berdiskusi dengan guru bidang studi prgram keahlian. Kegiatan 
workshop tampak pada gambar 1 dan 2 berikut :

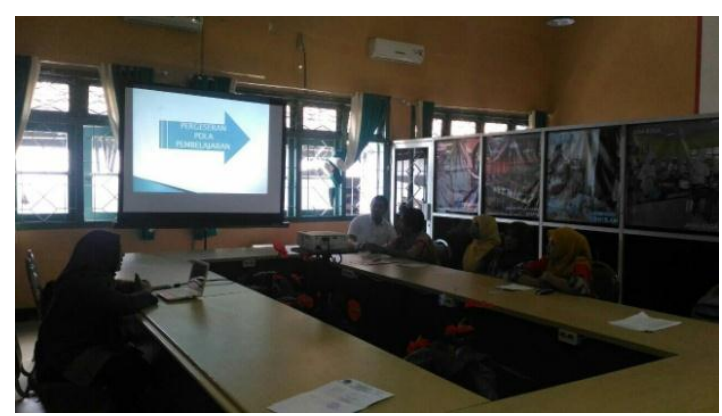

Gambar 1. Penyampaian materi

Mengingat padatnya geiatan guru dan pengabdi, maka masih perlu dilakukan pendampingan kepada setiap peserta agar dapat menyusun modul yang nantinya dapat diterapkan di sekolah masingmasing. Adapun pelaksanaannya adalah pada bulan September hingga November 2017.

\section{KESIMPULAN}

Pengabdian pada masyarakat dalam bentuk workshop penyusunan modul kontekstual pada guru SMK Malang adalah (a) menyusun modul matematika yang memiliki karakteristik program keahlian, (b) soal yang disusun merupakan soal matematika yang dikaitkan langsung dengan permalahan sesuai dengan kompetensi keahlian. Kegiatan Pendampingan selama kurang lebih 2 bulan untuk mendapatkan produk modul sesuai kompetensi keahlian yang ada.

\section{DAFTAR PUSTAKA}

[1] Wulandari, T.C. 2016. Pengembangan Modul Barisan dan Deret berbasis Kontekstual. Jurnal Inspirasi Pendidikan. Vol.6.(2) 